\title{
Pengembangan Media Pembelajaran Statistika Berbasis Multimedia
}

\author{
Devi Silvia Panjaitan \\ Universitas Negeri Medan, Jl. Willem Iskandar Pasar V Medan, Sumatera Utara, Indonesia \\ devisilvia915@gmail.com
}

\begin{abstract}
Abstrak-Di era perkembangan teknologi yang pesat ini, diperkukan penggunaan dalam segala aspek. Tak terlepas juga dunia Pendidikan yang harus mengadpataikan diri denagn teknologi dan membentuk jembatan yang mengantarai teknologi dan dunia Pendidikan. Salah satu cara yang dapat digunakan adalahd dengan menerpakan sistem dengan teknologi. Diantaranta dapat diterapkan dengan menggunakan media belajara yangberbasis multimedia. Peranan media pembelajaran dalam proses belajar dan mengajar sangat penting dilaksanakan oleh para pendidik saat ini, karena peranan media pembelajaran dapat digunakan untuk menyalurkan pesan pengirim kepada penerima dan melalui media pembelajaran juga dapat membantu peserta didik untuk menjelaskan sesuatu yang disampaikan oleh pendidik. Oleh sebab itu, pendidik harus dapat menyajikan media pembelajaran yang baik bagi perserta didik di era saat ini.
\end{abstract}

Kata Kunci: pembelajaran multimedia, statistika

Abstract-In this era of rapid technological development, the use of technology in various aspects is greatly enhanced. It is also inseparable in the world of education which must adapt itself to technology and bridge the technology and education world by implementing technology-based systems. Among them can be applied using multimedia-based learning media. The role of instructional media in the teaching and learning process is very important to be carried out by educators today, because the role of instructional media can be used to channel the sender's message to the recipient and through learning media and can also help students to explain something conveyed by the educator. Therefore, educators must be able to present good learning media for students in the current era.

Keywords: multimedia learning, statistics

\section{PENDAHULUAN}

Teknologi telah membawa hampir seluruh bagian kehidupan pada era baru yang menuntuk penggunaannya. Perkembangan teknologi juga memberikan pengaruh pada dunia Pendidikan. Pengaruh ini membuat Pendidikan mengalami perubahan baik dalam muatan kurikulum, proses belajar mengajar, peran pendidik, dan juga fasilitas yang mana media pembelajaran juga merupakan bagian darinya. Karena untuk menghasilkan peserta didik yang tidak hanya mampu bertahan pada era ini namun juga terbiasa dengan teknologi pada era ini, diperlukan sistem Pendidikan yang sesuai dengan perkembangan teknologi pada era saaat ini.

Media pembelajaran adalah sebuah perantara bagi peserta didik untuk belajar. Kata "media" berasal dari bahasa Latin "medium" yang berarti "perantara" atau "pengantar". Lebih lanjut, media merupakan sarana penyalur pesan atau informasi belajar yang hendak disampaikan oleh sumber pesan kepada sasaran atau penerima pesan tersebut. Dunia pendidikan juga telah memanfaatkan software untuk membuat metode aplikasi pembelajaran interaktif dengan konsep multimedia[harvei].Penggunaan media pengajaran dapat membantu pencapaian keberhasilan belajar. Ditegaskan oleh Danim bahwa hasil penelitian telah banyak membuktikan efektivitas penggunaan alat bantu atau media dalam proses belajarmengajar di kelas, terutama dalam hal peningkatan prestasi siswa. Alat bantu pembelajaran merupakan gambaran dari media pembelajaran. Interaksi langsung antara siswa dengan komputer merupakan konsep media yang interaktif [2]

Oleh karena itu, pada era saat ini sangat perlu mengembangkan media pembelajarn yang sesuai dengan materi ajar dan juga memanfaatkan teknologi. Pendidik harus dapat memilih, menggunaak, atau menciptakan media pembelajaran bagi peserta didiknya. Salah satu bentuk media pembelajaran terbeut adalah dengan memanfaatkan konsep multimedia pembelajaran. Dengan memadukan konsep multimedia (penggunaan teknologi) dan materi ajar, maka akan menghasilkan media pembelajaran yang menarik bagi siswa.

\section{LANDASAN TEORI}

\subsection{Multimedia Pembelajaran sebagai Media Pembelajaran}

Beberapa pakar pedidikan menyampaikan Pengertian media pembelajaran anatara lain sebagai berikut ini. Menurut Asosiasi Teknologi Komunikasi Pendidikan (AECT), media pembelajaran adalah segala sesuatu yang digunakan orang untuk menyalurkan pesan. Mulyani Sumantri menuliskan: menurut 
Bringgs (1970) ialah segala alat fisik yang dapat menyajikan pesan serta perangsang peserta didik untuk belajar, contoh buku, film, kaset [1,4].

Menurut Warsita (2008) mendefinisikan bahwa multimedia pembelajaran interaktif dapat didefinisikan sebagai kombinasi dari berbagai media yang dikemas (diprogram) secara terpadu dan interaktif untuk menyampaikan pesan pembelajaran tertentu. Hubungan antara pesan dan media, media disini bertindak sebagai pesan [4].

Multimedia pembelajaran merupakan satu bentuk teknologi yang dapat dijadikan media alternatif dalam pembelajaran. Penggunaan multimedia dapat merangsang dan meningkatkan motivasi siswa dalam pembelajaran. Masuknya multimedia dalam pembelajaran dapat menciptakan suasana yang menyenangkan dalam belajar karena multimedia menggabungkan beberapa unsur media sehingga proses pembelajaran dengan menggunakan multimedia lebih menarik[2].

Multimedia pembelajaran dapat dikembangkan atas dasar asumsi bahwa proses komunikasi dalam pembelajaran akan lebih bermakna, karena multimedia pembelajaran ini merupakan kombinasi berbagai unsur media yang terdiri dari teks, grafis, foto, animasi, video dan suara yang disajikan secara interaktif dalam media pembelajaran.

\subsection{Keunggulan Multimedia Pembelajaran}

Para pakar pendidikan sering menganjurkan bahwa dalam melaksanakan proses pembelajaran sebaiknya pendidik menggunakan media yang lengkap, sesuai dengan keperluan dan menyentuh berbagai indra. Untuk memenuhi keperluan itu, maka penggunaan multimedia adalah salah satu alternatif pilihan yang baik untuk pengajaran dan pembelajaran yang berkesan.

Pembelajaran dengan menggunakan multimedia banyak memiliki keunggulan sebagai media pembelajaran menurut Newby, diantaranya sebagai berikut $[1,2,3]$.

1. Memberikan pembelajaran dengan penyimpanan informasi yang baik;

2. Desain pembelajaran yang ditunjukan bagi siswa dengan karakteristik belajar yang berbeda;

3. Langsung ditujukan bagi domain pembelajaran efektif tertentu;

4. Menghadirkan pembelajaran yang realistis;

5. Dapat meningkatkan motivasi peserta didik;

6. Menuntut siswa agar lebih interaktif;

7. Kegiatan pembelajaran lebih bersifat individual;

8. Memiliki konsistensi materi yang diberikan; dan

9. Siswa mempunyai pengendalian terhadap kecepatan belajar setiap individu.

\subsection{Statistika}

Statistika dan Komputasi merupakan ilmu yang meliputi pengenalan teknik-teknik dasar statistika serta aplikasinya untuk pembuatan rancangan percobaan, pengumpulan data, serta analisis data sekaligus mengkomunikasikannya secara oral maupun tulisan. Penggunaan piranti lunak paket statistik sederhana untuk pengelolaan data serta interpretasinya.Adapun beberapa materi yang akan dibahas dalam perkuliahan Statistik dan Komputasi diantaranya pengetahuan umum pentingnya statistik, simpangan baku, median, mean, modus, frekuensi, distribusi binmial, ultinomial, poisson, selang kepercayaan, langkah pengambilan dan pengujian sampel, hipotesa [5].

Statistik adalah ilmu yang mempelajari tentang seluk beluk data yaitu tentang pengumpulan, pengolahan, penafsiran dan penarikan kesimpulandari data yang berbentuk angka-angka. Ada tiga hal pokok yang terkandung dalam statisktik, yaitu : 1). Data, 2). Perlakuan dari data, berupa pengumpulan, pengolahan/analisis, penafsiran dan penarikan kesimpulan; 3). Angka-angka [6].

\section{HASIL DAN PEMBAHASAN}

Dalam pengembangan multimedia pembelaran, dapat diciptakan sebuat media belajar yang mempermudah proses belajar peserta didik. Penulis mengambil contoh pembuatan multimedia pembelajaran dengan menggunakan software Adobe Flash. Produk yang dihasilkan adalah aplikasi belajar yang mengintegrasikan beberapa cara belajar. 
Produk akhir dalam penelitian ini yaitu multimedia pembelajaran yang digunakan sebagai media pembelajaran. Aplikasi terdiri dari halaman-halaman yang saling terhubung menggunakan tombol-tombol. Halaman utama berisi beberapa tombol yang berfungsi untuk mengakses halaman yang diinginkan. Tombol-tombol yang berada di halaman utama tersebut antara lain yaitu materi belajar, contoh soal, dan soal Latihan seperti pada gambar di bawah ini.

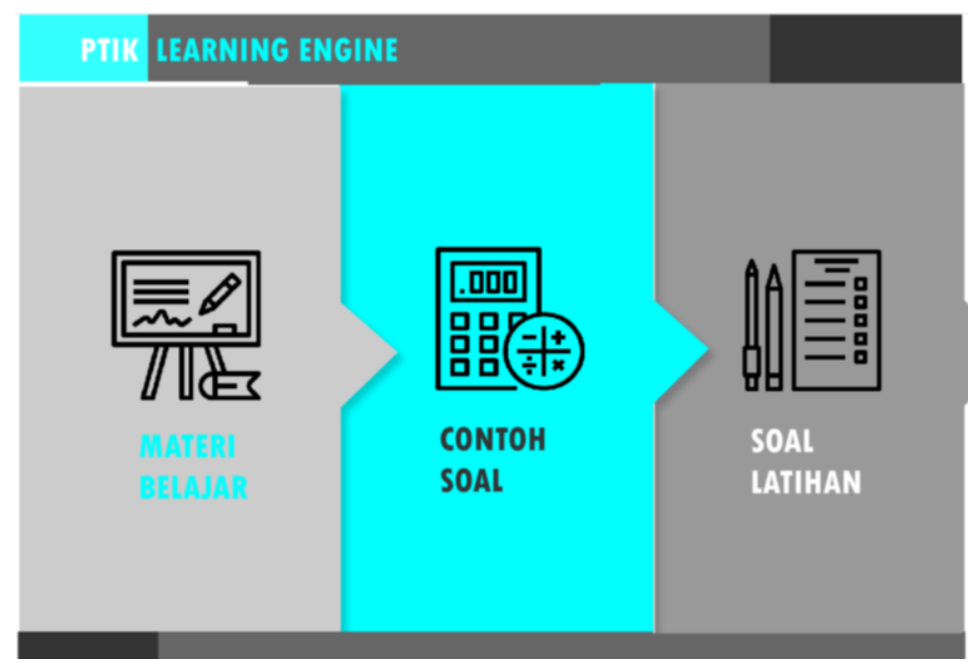

Gambar 1. Halaman Utama

Pada bagian materi belajar akn disuguhkan tampilan materi pelajaran yang akan diajarkan pada siswa. Sehingga siswa dapat belajar dengan menarik tidak hanya seperti tampilan pada buku teks. Tombol untuk Kembali ke menu utama hanya dibuat pada bagian akhir materi pembelajaran, agar peserta didik mempelajari materi belajar sampai dengan akhir.

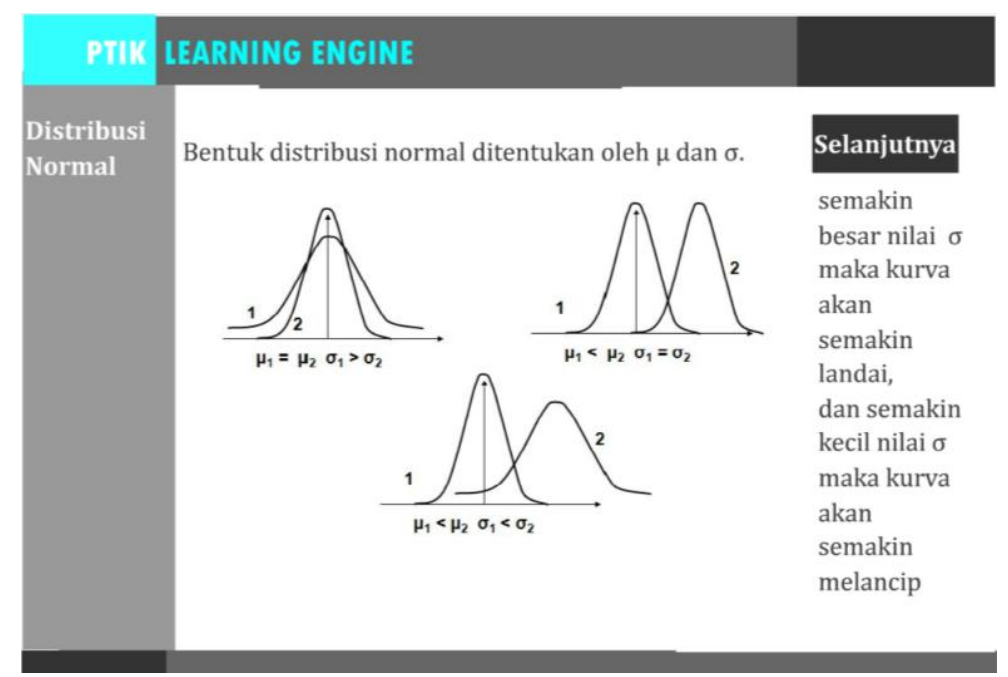

Gambar 2. Materi

Berikutnya akan dibahas mengenai tampilan contoh soal,aplikasi ini memaparkan bacontoh soal yang dapat dijelaskan Kembali oleh pendidik sehingga peserta didik lebih mengerti. Jika ingin Kembali ke menu utama, maka tinggal mengklik tombol "menu utama". 


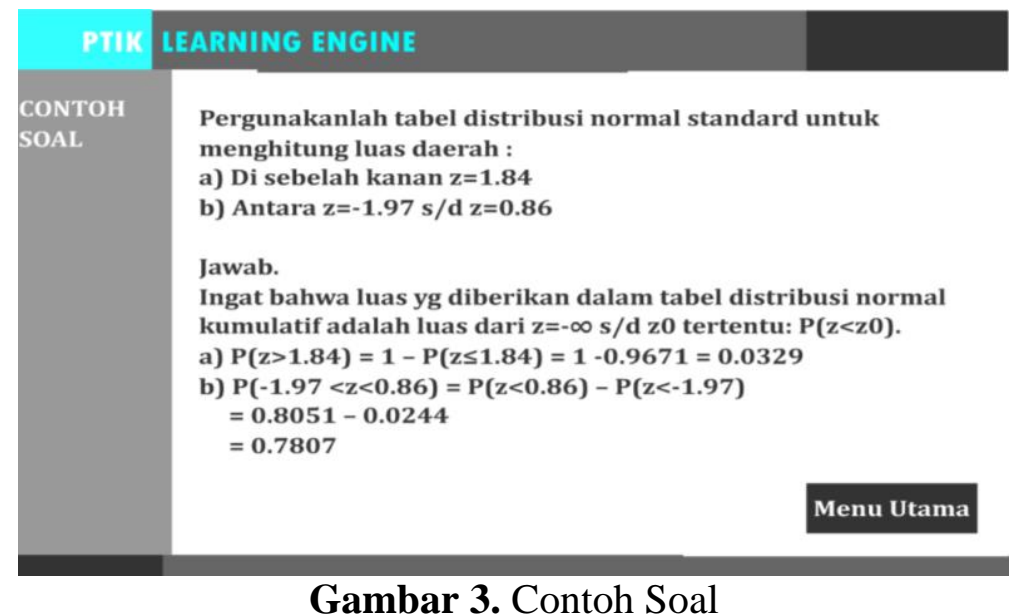

\section{Gambar 3. Contoh Soal}

Pada menu soal pada bagian awal, akan muncul tombol "mulai", yang jika di klik maka akan muncul tampilan soal seperti pada gambar dibawah ini. Peserta didik akan memilih jawaban yang paling tepat dan kemuaan akan muncul skornya diakhir. Dalam tampilan soal Latihan ini, peserta didik harus mengisi smeua soal agar dapat memperoleh skor dan Kembali ke "menu utama" atau jika peserta didik ingin mengulangi Kembali latihannya maka dapat mengklik tombol "ulangi”.

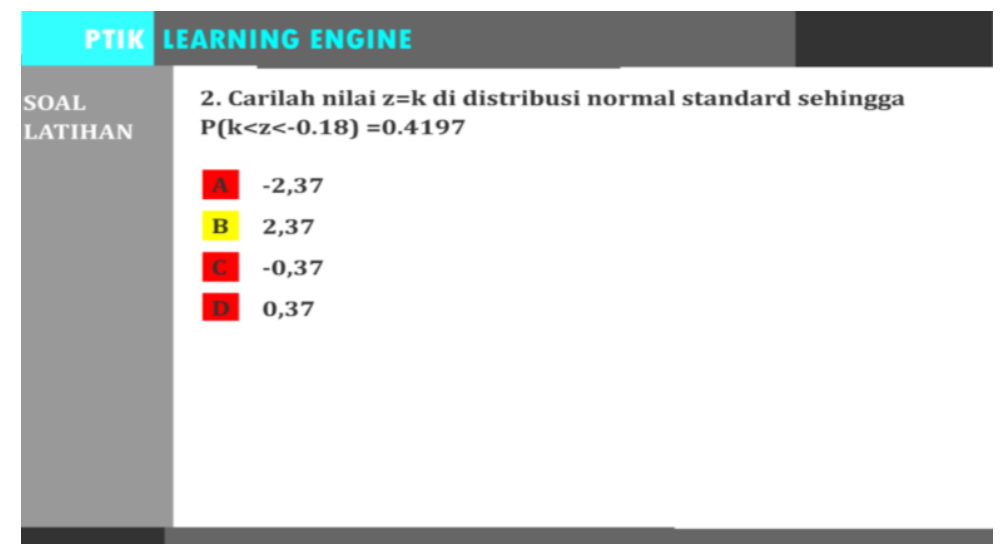

Gambar 4. Latihan

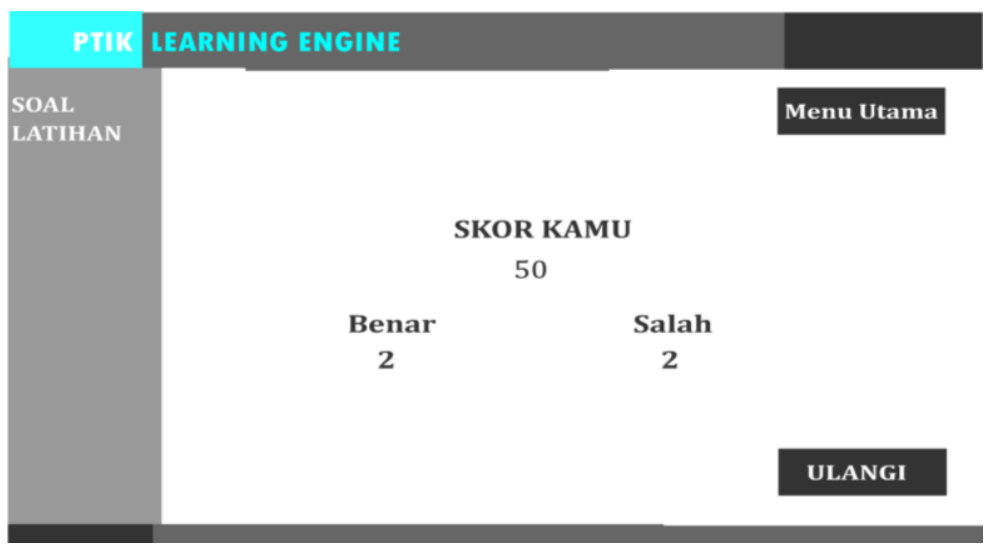

Gambar 5. Skor

Pada tampilan yag ditampilkan dengan aplikasi ini, digunakan visualisasi yang tidak membosankan dan meminta peserta didik untuk memberikan tindakan dengan menekan tombol yang ada. Dengan aktifitas peserta didik yang demikian, maka peserta didik akan tertarik untuk belajar dengan melakukan interaksi dengan aplikasi belajar yang disediakan. 
Berdasarkan data hasil uji coba yang diperoleh maka pengembangan multimedia pembelajaran pada mata pelajaran TIK kelas VIII dapat dikatakan layak untuk diterapkan di sekolah. Berdasarkan penelitian yang telah dilakukan diatas, maka Multimedia pembelajaran ini mudah digunakan oleh pengguna dengan perintah-perintah yang bersifat sederhana, dan pengguna secara aktif dapat memilih menu yang diinginkan. Dengan menggunakan aplikasi ini atau juga dapat mencipatakan multimedia pembelajarajn denagn software Adobe Flash, maka dapat dijadikan alternative dalam pengadaan media pembelajaran di sekolah.

\section{KESIMPULAN}

Salah satu cara untuk mengembangkan media belajar bagi peserta didik adalah dengan memanfaatkan konsep multimedia pembelajaran yang mana dapat dibangun dengan menggunakan software Adobe Flash. Dengan menampilkan aplikasi multimedia pembelajaran, selain mempermudah peserta didik memahami materi pelajarannya, media belajar ini meningkatkan minal belajar peserta didik yang mengintegrasikan teknologi sehingga anak dapat melaksakan proses belajar dengan baik. Jadi dapat disimpulkan bahwa multimedia pembelajaran ini memiliki peluang pengembangan yang tinggi pada lingkungan pembelajaran dan kemenarikan produk pada kriteria baik, hal ini dibuktikan dengan hasil pengumpulan data melalui studi Pustaka berdasarkan sumber tertulis atau literatur-literatir yang menjadi sumber dari penelitian ini.

\section{DAFTAR PUSTAKA}

[1] N. Nopriyanti and P. Sudira, "Pengembangan multimedia pembelajaran interaktif kompetensi dasar pemasangan sistem penerangan dan wiring kelistrikan di SMK," J. Pendidik. Vokasi, vol. 5, no. 2, 2015.

[2] H. D. Hutahaean and P. M. Hasugian, "Aplikasi Pembelajaran Kriptograpi berbasis Mobile menggunakan Computer Assisted Instruction," vol. 4, no. 1, pp. 2-5, 2019.

[3] T. Tafonao, "Peranan Media Pembelajaran Dalam Meningkatkan Minat Belajar Mahasiswa," J. Komun. Pendidik., vol. 2, no. 2, p. $103,2018$.

[4] J. Kuswanto et al., "Pengembangan Multimedia Pembelajaran pada Mata Pelajaran Teknologi Informasi dan Komunikasi Kelas VIII," Innov. J. Curric. Educ. Technol. IJCET, vol. 6, no. 2, pp. 58-64, 2017.

[5] L. M. Nasution, " Statistik Deskriptif."Vol. 14, no. 1, pp. 49-55, 2017.

[6] R. Sary. MM and T. Listyorini,"ANALISIS STATISTIK UNTUK PENGUKURAN NILAI PEMBELAJARAN LOGIKA INFORMATIKA (STUDI KASUS : PROGRAM STUDI TEKNIK INFORMATIKA),"vol. 4, no. 1,pp. 71-81, 2013. 